\title{
A DISSIMULAÇÃO E A NUDEZ DA IMAGINAÇÃO MORAL EM "A IGREJA DO DIABO"
}

\section{ANTÔNIO JOAQUIM PEREIRA NETO}

\author{
Instituto Federal da Bahia
}

Paulo Afonso, Bahia, Brasil

Resumo: O artigo analisa o conto "A igreja do diabo". A proposta é demonstrar que Machado de Assis faz de sua ficção um instrumento de análise crítica dos fundamentos morais constitutivos da filosofia clássica e da doutrina cristã. Ao expor a inconstância das escolhas e da conduta humana, o escritor brasileiro coloca em questão a efetivação, no mundo das ideias, do bem, da retidão moral e da verdade construídas pela episteme ocidental. Nota-se que seu discurso é marcado retoricamente pela dissimulação de sua presença, sobretudo quando manipula os códigos simbólicos da figuração ficcional na elaboração de efeitos cujos sentidos são determinados pela leitura cuja verossimilhança é o pressuposto de uma razão discursiva passível de ser reconhecida na concatenação aguda dos seus artifícios.

Palavras-chave: Machado de Assis; Dissimulação; Filosofia; Cristianismo; Moral.

\section{DISSIMULATION AND NAKEDNESS OF THE MORAL IMAGINATION IN "THE DEVIL'S CHURCH"}

\begin{abstract}
This article examines the short story "The Devil's Church" with the aim of demonstrating that Machado de Assis uses his fiction to critically analyze the moral foundations of classical philosophy and Christian doctrine. By exposing the fickleness of human choices and conduct, the Brazilian writer questions the implementation of such concepts as good, moral rectitude and truth in the world of ideas as they are constructed by the Western episteme. It is noted that his discourse is rhetorically marked by the dissimulation of his presence, mainly by his manipulation of the symbolic codes of fictional figuration in developing effects whose meanings are defined by the reader,
\end{abstract}


which assumes a discursive logic that may be recognized by the reader thanks to the way Machado deftly strings together his artifices.

Keywords: Machado de Assis; Dissimulation; Philosophy; Christianity; Moral.

s questões relacionadas à verdade e à virtude moral sempre estiveram
no cerne da abordagem filosófica e ficcional. Um problema
característico proposto pelos filósofos do mundo clássico aspirava a uma resolução: "a virtude pode ser ensinada? Há uma moral em forma de saber transmissível?” (RICOEUR, 2014, p. 28). Se à filosofia destinava-se a tarefa de conduzir o homem para o encontro com a felicidade e com as ideias que eram boas e belas nelas mesmas, ${ }^{1}$ a ficção, de uma forma específica, se constituía como aquilo que poderia fazê-lo se aproximar desse bem, pela via de uma ordem enunciativa que tomava o verossímil ${ }^{2}$ como referência essencial. Não obstante ter sido esta a forma dominante pela qual foram replicados historicamente os valores éticos e científicos das comunidades que os tomavam como autoridades, não menos importância e valor deve merecer o cristianismo enquanto doutrina na avaliação que fazemos do modo como se constituíram as verdades morais no Ocidente ao longo da tradição que o legitimava.

Dessa forma, o presente artigo analisa o modo como Machado de Assis faz de sua ficção um instrumento de análise crítica dos fundamentos morais constitutivos da filosofia clássica e da doutrina cristã, compondo um discurso marcado retoricamente pela dissimulação de sua presença enquanto sujeito enunciador dos valores veiculados na narrativa, ao manipular os códigos da representação ficcional na configuração de uma narrativa cuja racionalidade discursiva é alcançada pelo efeito eficaz do seu artifício. O autor de Esaú e Jacó, contrapondo-se às convenções do discurso filosófico, "pode também dissimular-se e falar-se como outro, expondo-se duplo e múltiplo no discurso, desapropriando-se em deformações que ocultam a verdade" (HANSEN, 1992, p. 20).

\footnotetext{
${ }^{1}$ A filosofia considera que a felicidade nós "a escolhemos sempre por si mesma, e jamais em vista de outra coisa; a honra, o prazer e todas as virtudes, também nós as escolhemos por si mesmas, mas as escolhemos também em favor da felicidade" (ARISTÓTELES, 2016, p. 24).

2 "O que se costumou traduzir por 'verossimilhança' prescinde em grego do 'vero' (o verdadeiro) - o termo 'eikós' compreendendo as esferas do semelhante, do adequado e do conveniente. Isso significa que não se tem em vista a semelhança do que se mimetiza com algo verdadeiro externo à obra" (BRANDÃO, 2018, p. 14.).
} 
Nota-se de que modo a referência aos moralistas do mundo presente na narrativa que será investigada nos credencia para a análise de alguns tratados do filósofo Montaigne, a partir dos quais é possível revisar as pressuposições morais ficcionalizadas por Machado de Assis. É neste contexto que Machado realiza, no conto "A igreja do Diabo", a contrafação jocosa dos fundamentos de determinação dessas duas influentes tradições de pensamento: aquela relativa ao ensinamento da virtude promovido pelo debate filosófico e a outra relativa aos pressupostos da moral do cristianismo. Na hipótese deste texto, a ficção machadiana nos permitirá ler tanto a relatividade das máximas filosóficas quanto a impossibilidade constitutiva de realização terrena da questão doutrinária agostiniana: "Por que não nos esforçamos para que, já nesta vida, as inclinações da carne se transformem para melhor e não se oponham ao espírito com movimentos desordenados?” (AGOSTINHO, 2002, p. 64).

O texto em questão objetiva evidenciar como Machado dialoga com a tradição da doutrina cristã e com a dos tratados de filosofia moral. Isso será feito a partir de uma técnica que, ao expor o artifício retórico como causa eficiente da enunciação dos personagens, realiza o desnudamento do processo de defesa dos valores morais e a exposição ficcional da inconstância de nossos afetos - aquela segundo a qual as fundamentações morais figuradas na narrativa são objetos de crença destituídos de fundamento natural ou metafísico. E, por essa via, questionamos: estaria Machado bebendo na fonte do ensaísta Michel de Montaigne, ao tornar suas pretensões à certeza e à verdade desprovidas de razão e ao formalizar uma ficção cuja leitura aguda possibilita projetar o efeito de que "todo e qualquer discurso é reduzido ao nível da opinião" (SCORALICK, 2016, p. 29)?

A estória está escrita num manuscrito beneditino, que narra como o Diabo concretizou a ideia de fundar uma igreja com o fim de alcançar uma notoriedade frente ao "papel avulso que exercia desde séculos, sem organização, sem regras, sem cânones, sem ritual, sem nada” (ASSIS, 2007, p. 183). Para tamanho empreendimento e com o objetivo de tornar o seu credo o núcleo universal dos espíritos, ele comunica a Deus a ideia e o desafia com a certeza de que obteria a vitória final do seu reinado contra o dos homens. A autoridade do seu argumento funda-se numa experiência secular cuja retórica não passa despercebida por Deus:

Só agora concluí uma observação, começada desde alguns séculos, e é que as virtudes, filhas do céu, são em grande número comparáveis a rainhas, cujo manto de veludo rematasse em franjas de algodão. Ora, eu 
proponho-me a puxá-las por essa franja, e trazê-las todas para a minha igreja; atrás delas virão as de seda pura...

- Velho retórico! murmurou o Senhor. (ASSIS, 2007, p. 185)

Entendida como o núcleo de significação do conto, essa metáfora torna plausíveis leituras que apontam para as duas ordens discursivas mencionadas: a que propõe a definição da virtude pelo uso da máxima filosófica ${ }^{3}$ e a que investe na noção de virtude cara ao debate teológico, desenvolvida em torno da pressuposição de que Deus, "a fim de libertar nosso corpo terreno da corrupção externa” (PELIKAN, 2014, p. 242), tingiu "a alma do homem com a estabilidade e imutabilidade de sua própria natureza, tornando-a participante de sua divindade impassível” (PELIKAN, 2014, p. 242). A inteligibilidade demanda, na perspectiva aqui adotada, uma remissão ao contexto de uma narrativa em que a roupa é usada como utensílio para iludir uma sociedade cujo imaginário é regido por códigos simbólicos e sociais de representação.

É o caso de uma estória que consta do livro El conde Lucanor, de d. João Manuel, intitulada "Lo que sucedió a un rey con los burladores que hicieron el paño". Inserido no contexto medieval, esse livro compõe um acervo de historietas, "exemplos", de caráter didático-doutrinal que tinha "o objetivo essencial de orientar o comportamento social e moralizar a conduta humana" (SILVEIRA, 2005, p. 149). Ressignificada modernamente, essa historieta ganhará novos contornos no universo social oitocentista, permitindo-nos utilizá-la como referência discursiva apropriada para a construção do sentido da metáfora machadiana.

No conto "A roupa nova do rei”, bem conhecido por ser a imitação dessa historieta, a reflexão passível de ser elaborada sobre a realeza é iluminadora. Analisemos o que se revela nessa estória: "Há muitos anos atrás, em um reino bem distante, vivia um imperador mais conhecido por seu orgulho e elegância do que por seus feitos e atos de bondade" (SCHWARCZ, 1998, p. 25). Reconhecido mais pela sua vaidade do que pelas suas virtudes morais, o rei seria presenteado por dois alfaiates com uma roupa cujo aspecto precioso e secreto, visto somente pelos sábios e mais inteligentes, seria capaz de forjar a evidência da natureza transcendente de seu poder, que estaria além do inteligível, mas cujos "limites entre o visível e o invisível estariam só fragilmente delineados" (SCHWARCZ, 1998, p. 26).

\footnotetext{
${ }^{3}$ Aqui a enunciação do Diabo nos permite pressupor uma relação com a concepção de Montaigne, para o qual "a virtude faria que um homem mostrasse sempre igual resolução", e, portanto, como ela "vale por si mesma, se para outro fim tomamos a sua máscara, logo ela no-la arranca da cara" (MONTAIGNE, 2016, p. 357).
} 
O grandioso traje, dotado de propriedades milagrosas e efeitos maravilhosos, tornaria o invisível materialmente visível e palpável aos olhares dos súditos convertidos à eficácia mágica da realeza, aos seus fundamentos místicos e aos seus rituais de consagração, uma vez que, "na corte, ninguém falava do que via ou do que não via; ao contrário, todos elogiavam a beleza da veste, o esplendor da figura do rei, tão bem adornado com suas novas vestes" (SCHWARCZ, 1998, p. 26). Mas esse milagre só duraria o tempo em que uma criança, ainda não anestesiada pela eficácia simbólica dos signos de ostentação daquele sistema, manifestasse que o invisível continuava invisível e que não existia uma nova roupa do rei, pois ele estava nu, tornando-se, a partir de então, vítima dos risos e das gargalhadas dos súditos.

Com efeito, a nudez do rei desmascarava esse jogo de encantamento produzido pelos signos de distinção social que legitimavam a hierarquia funcional daquele tipo de sociedade. Diante da realidade, a nobreza era desvelada pela natureza artificial de suas representações. Eis por onde é possível descortinar a metáfora do Diabo machadiano, por meio de uma alusão aos códigos de representação de uma sociedade monárquica cujos valores morais são fragilmente delineados. Revitalizada dessa maneira, a estória pode ser lida como uma ironia aos códigos de representação da sociedade de corte.

Todavia, não seria verossímil atribuir esse sentido ao texto originado no medievo ibérico, uma vez que nele "tratava-se de afirmar os fundamentos de uma hierarquia moral, como forma de referendar os atributos e noções fundamentais de toda uma ordem social” (SILVEIRA, 2005, p. 156). Na historieta original, os que não vissem o precioso e secreto traje eram acusados de não serem filhos do rei:

[...] tres pícaros fueron a palacio y dijeron al rey que eran excelentes tejedores, y le contaron cómo su mayor habilidad era hacer un paño que sólo podian ver aquellos que eran hijos de quienes todos creían su padre, pero que dicha tela nunca podría ser vista por quienes no fueran hijos de quien pasaba por padre suyo. (MANUEL, 2004, p. 70).

Assim, posto que esse tipo de cegueira correspondesse a um estado de orfandade numa terra sem pai, metáfora da ausência dos vínculos funcionais aristocráticos, todos os caracteres enganados se recusavam a dizer a verdade sob pena de perderem a honra de suas respectivas posições, inclusive o próprio rei: "Cuando el rey los vio tejer y decir cómo era la tela, que otros ya habían visto, se tuvo por muerto, pues pensó que él no la veía porque no era hijo 
del rey, su padre, y por eso no podía ver el paño, y temió que, si lo decía, perdería el reino" (MANUEL, 2004, p 71).

Com efeito, o sentido político da estória também pressupunha um sentido cristão, pois os "pícaros" que enganam o rei e seus súditos negam o corpo harmonioso promovido pela hierarquia e a conduta ética de um bom cristão. Eis a finalidade pedagógica dessa prosa de exemplos, formada por "ditos sapienciais de sentenças e provérbios voltados à orientação da conduta individual e social a partir de contextos e situações vivenciais diversas" (SILVEIRA, 2005, p. 174).

Todavia, no caso machadiano, é outra a verossimilhança, pois era outro o contexto da enunciação. O anúncio da rainha feito pelo Diabo na sua análise da virtude pressupõe uma experiência com a Monarquia, sistema de governo no qual a boa aparência constitui uma convenção que ganha relevo nos circuitos da socialização.

Na França setecentista, como nos ensina a vida da rainha Maria Antonieta, "o vestuário era a moeda de aceitação social e sobrevivência política” (WEBER, 2008, p. 23), e uma nobre ocupando uma certa posição nunca "devia subestimar o poder da censura" social "que equiparava beleza principesca com virtude, aparência superficial com essência subjacente" (WEBER, 2008, p. 31). Antes arquiduquesa da Casa de Habsburgo, a história nos revela que o vínculo real adquirido pela rainha Maria Antonieta com a Casa de Bourbon demandava a remoção do seu vínculo simbólico com a Casa da Áustria, o que pressupunha um "tradicional ritual de desnudamento" (WEBER, 2008, p. 4). "E essa questão da nudez não era simplesmente uma obrigação entre as muitas que agora constituíam seu mandato real" (WEBER, 2008, p. 35), posto que "esperava-se que Maria Antonieta assegurasse a continuidade dinástica da linhagem Bourbon” (WEBER, 2008, p. 36). Nesse ritual, a futura rainha, "depurada de suas marcas austríacas, estava pronta para que escrevessem nela os códigos e interesses exclusivos da monarquia francesa" (WEBER, 2010, p. 37).

Finalmente, se a virtude estava na superfície, na aparência, é pertinente a leitura pela qual as franjas de algodão não representam um inconveniente insignificante, mas a parte não nobre de uma veste que precisa ser substituída por seda pura, uma aparência superficial cuja essência subjacente precisa ser substituída pela virtude da igreja do Diabo. Como Maria Antonieta, os súditos da igreja de Deus deveriam passar pelo ritual do desnudamento, revelando, ao invés da aparência, a essência de suas verdadeiras paixões. 
Nesse sentido, é possível a leitura do Diabo como crítico do aspecto imitativo, artificial e ritualístico dessa representação. Aqui, a metáfora se converte numa máxima, pela qual as virtudes morais seriam, por assim dizer, inautênticas, artificiais e ritualísticas, podendo ser utilizadas ao sabor das conveniências individuais. Afinal, se as virtudes são "comparáveis a rainhas, cujo manto de veludo rematasse em franjas de algodão", essa semelhança também poderia ser verificada nos reis, cujas vestes constituem somente a representação ideal visível do que interessa aos membros daquela civilização.

Retiradas as vestes e as franjas de algodão, as virtudes morais estariam desnudadas, perdendo a sua nobreza por não serem mais simuladas pela representação. Por essa leitura, o Diabo teria o monopólio da verdade moral, sendo o grande senhor da capacidade de evidenciar a farsa moral na qual vivem os homens. Apenas ele substituiria o engodo pela realidade, o manto de veludo sob o qual se escondia a humanidade pela seda pura.

Desnudada a moralidade humana, todo o edifício filosófico formalizado pelas virtudes cristãs estava comprometido, não obstante a objeção do Senhor: "tudo o que dizes ou digas está dito e redito pelos moralistas do mundo" (ASSIS, 2007, p. 185). Por esse caminho é preciso acirrar o debate em torno da questão moral, tomando o Diabo como alegoria da cosmovisão do ensaísta Michel de Montaigne. Eis o que diz esse reconhecido moralista:

Mostra-me a experiência que vai grande diferença entre as súbitas determinações da alma e sua conduta habitual. Bem vejo que nada nos é vedado, nem mesmo ultrapassar a própria divindade, disse alguém; há maior mérito, por exemplo, em ser impassível por força de vontade do que por tendência natural. (MONTAIGNE, 2016, p. 677)

No ensaio "Da virtude", Michel de Montaigne presume a impossibilidade de tal mérito pelos casos extraordinários ${ }^{4}$ que denotariam uma imaculada conduta exercida em desacordo com a tendência natural. Ao ironizar a pretensiosa harmonia entre as determinações da alma e uma conduta impassível, o filósofo "acusa o projeto neoestoico de supressão das paixões (ideal de conduta perfeitamente racional dos sábios) não só de inútil, na medida em que propõe um modelo moral inacessível aos homens, mas de ser nocivo, já que vai de encontro às suas inclinações empiricamente observáveis" (busca de prazer, aversão à dor) (SCORALICK, 2016, p. 31). Essa

4 “É costume, nas Índias, terem os homens várias mulheres e a preferida matar-se por ocasião da morte do marido" (MONTAIGNE, 2016, p. 678). 
acusação o aproxima do Diabo machadiano, para o qual, no ritual de desnudamento da igreja cristã, a nova roupa evidencia o homem movido pelas suas inclinações naturais. Portanto, como a referência é monárquica, verificase que sem "uma técnica ou cálculo prudente de viver em sociedade", sem a educação de "uma moderna racionalidade de corte" (PÉCORA, 2001, p. VIII), o homem será dominado pelas paixões.

Partindo dessas considerações, o Diabo nos possibilita ler a igreja de Deus como portadora de uma doutrina cujo conceito de virtude se revela como uma máscara social, visto que seriam as paixões que governariam a conduta dos homens. Nessa busca pelo prazer, ele se transformaria em amor-próprio, interesse, venalidade, luxúria, vaidade e tantos outros "vícios" empiricamente observáveis e, ao mesmo tempo, reveladores de uma conduta social materializada na contramão da impassibilidade divina ${ }^{5}$ e da noção de virtude, enquanto "disposição de caráter relacionada a uma escolha deliberada que ocupa uma posição central determinada pela razão” (ARISTÓTELES, 2016, p. 48).

Todavia, Deus expôs o caso de um ancião que:

[...] depois de uma vida honesta, teve uma morte sublime. Colhido em um naufrágio, ia salvar-se numa tábua; mas viu um casal de noivos, na flor da vida, que se debatiam já com a morte; deu-lhes a tábua de salvação e mergulhou na eternidade. Nenhum público: a água e o céu por cima. Onde achas aí a franja de algodão? (ASSIS, 2007, p. 185)

Metáfora do fingimento social, a franja de algodão simula o que não é, pois sendo a inclinação natural o combustível do comportamento humano, esse adorno apenas pressupõe o fingimento de uma vida idônea fantasiada por um sistema social legitimado pela etiqueta das representações. Eis o alicerce da religiosidade cristã, negada pelo Diabo, que via na atitude do ancião um exemplo de misantropia, ao revelar: "[...] deixar a vida aos outros, para um misantropo, é realmente aborrecê-los” (ASSIS, 2007, p. 186). A consciência do fundador da nova igreja era a de que o mundo moral não só era regido como também era e deveria ser determinado pela lógica do interesse:

Clamava ele que as virtudes aceitas deviam ser substituídas por outras, que eram as naturais e legítimas. A soberba, a luxúria, a preguiça foram reabilitadas, e assim também a avareza, que declarou não ser mais do que

\footnotetext{
${ }^{5}$ Nesse cenário, "a doutrina cristã é realmente a matriz e o princípio dessa anatomia moral que disseca o homem para nele celebrar a imagem da divindade" (OLIVEIRA, 2003, p. 148).
} 
a mãe da economia, com a diferença que a mãe era robusta, e a filha uma esgalgada. [...] A demonstração, porém, mais rigorosa e profunda, foi a da venalidade. Um casuísta do tempo chegou a confessar que era um monumento de lógica. A venalidade, disse o Diabo, era o exercício de um direito superior a todos os direitos. Se tu podes vender a tua casa, o teu boi, o teu sapato, o teu chapéu, cousas que são tuas por uma razão jurídica e legal, mas que, em todo caso, estão fora de ti, como é que não podes vender a tua opinião, o teu voto, a tua palavra, a tua fé, cousas que são mais do que tuas, porque são a tua própria consciência, isto é, tu mesmo? Negá-lo é cair no absurdo e no contraditório. [...] Todas as formas de respeito foram condenadas por ele, como elementos possíveis de um certo decoro social e pessoal; salva, todavia, a única exceção do interesse. [...] Com efeito, o amor do próximo era um obstáculo grave à nova instituição. (ASSIS, 2007, p. 188)

Contrapor-se a todas as formas de decoro social ${ }^{6}$ e pessoal significava fazer o encômio dos antigos vícios como norma predominante da vida social. Era essa a tese sustentadora de sua doutrina, que não admitia nenhuma forma de conduta que pudesse colocar em xeque a boa nova desses valores morais. $\mathrm{Na}$ defesa desses valores, o mau uso do interesse não poderia acontecer, sendo ele o núcleo da nova igreja. Ao construir uma igreja cujo objetivo era colocar o mundo às avessas, o Diabo evidencia o caráter transitório e histórico dos valores humanos; ao passo que nos permite vislumbrar o modo pelo qual ele demonstra a sua verdade, que era temida pela doutrina cristã. Eis o que está demonstrado no cristianismo agostiniano, o risco de o mundo se converter ao desconcerto: “[...] assim como a sabedoria parece loucura para os contestadores de Deus, do mesmo modo, o que chamamos loucura é sabedoria para os vencedores do demônio" (AGOSTINHO, 2002, p. 54).

É no seio do debate em torno da virtude moral que ocorre a disputa retórica entre Deus e o Diabo. Enquanto o Diabo promete "substituir a vinha do senhor, expressão metafórica, pela vinha do Diabo, locução direta e verdadeira" (ASSIS, 2007, p. 187), o primeiro o rechaça denominando-o de "Retórico e sutil!" (ASSIS, 2007, p. 186). Ambos condenam o uso dos artifícios, ao passo que se valem dos mesmos. Engenhoso no tratamento da eloquência, o "Diabo alçou brados de triunfo" e "todas as virtudes cuja capa de veludo acabava em franja de algodão, uma vez puxadas pela franja, deitavam a capa às urtigas e vinham alistar-se na igreja nova” (ASSIS, 2007, p. 189). A verdade

\footnotetext{
${ }^{6}$ Decoro: "mudar de manto para vestir-se conforme a estação da fortuna, não com a intenção de causar dano, mas de não sofrê-lo, que é o único interesse pelo qual se pode tolerar quem costuma valer-se da dissimulação" (ACCETTO, 2001, p. 19).
} 
estava finalmente nua, pois os homens, movidos por golpes astuciosos de eloquência, revelam-se parciais e contraditórios ${ }^{7}$ em suas escolhas morais: “[...] longos anos depois notou o Diabo que muitos dos seus fiéis, às escondidas, praticavam as antigas virtudes. Não as praticavam todas, nem integralmente, mas algumas, por partes, e, como digo, às ocultas" (ASSIS, 2007, p. 189).

As teses da unidade moral e das verdades essenciais são colocadas em xeque por uma narrativa que expõe a contingência dos conteúdos morais consagrados pelas tradições filosófica e cristã, uma vez que, da mesma forma que o homem não pode ser impassível como almeja a doutrina do cristianismo, "a caracterologia tradicional - tanto a da Ética a Nicômaco quanto a dos Caracteres de Teofrasto - é essencialista e tende a petrificar os seres" (OLIVEIRA, 2003, p. 125).

Não há aqui caractere que não esteja sujeito ao processo de revisão de suas opiniões. Todos podem ser mediados e interpelados por raciocínios e experiências reveladas em máximas filosóficas, excetuando talvez Deus, não obstante encerrar a sua visão com uma máxima cuja filosofia expressa a não unidade dos efeitos de sua doutrina: "Que queres tu, meu pobre Diabo? As capas de algodão têm agora franjas de seda, como as de veludo tiveram franjas de algodão. Que queres tu? É a eterna contradição humana” (ASSIS, 2007, p. 190).

Essa conclusão pressupõe a leitura de um circuito que contempla o eterno retorno de vícios e virtudes expostos por artifícios produtores de efeitos que ratificam também outras leituras verossímeis. Entre elas: a verossimilhança do pensamento segundo o qual Deus, se entendido como onipotente, é o grande dissimulador dos pecados dos homens por defender a impassibilidade do ancião diante da morte, sobretudo quando se tem em vista que "a dissimulação é a habilidade de não fazer ver as coisas como são" (ACCETTO, 2001, p. 27) e quando se acredita que "Deus é a própria verdade, que é a medida de toda a verdade sendo a primeira causa de todas as coisas" (ACCETTO, 2001, p. 10).

De outro modo, tendo em vista que o raciocínio da eterna contradição humana não era exclusivamente divino, mas também mundano, uma vez que já havia sido defendida a máxima da "instabilidade natural de nossos costumes e opiniões” (MONTAIGNE, 2016, p. 353), também é possível a leitura de que

\footnotetext{
${ }^{7}$ Essa contradição já fora abordada no discurso filosófico: "Todas as contradições em mim se deparam, no fundo como na forma. Envergonhado, insolente, casto, libidinoso, tagarela, taciturno, trabalhador, requintado, engenhoso, tolo, aborrecido, complacente, mentiroso, sincero, sábio, ignorante, liberal e avarento, e pródigo, assim me vejo de acordo com cada mudança que se opera em mim" (MONTAIGNE, 2016, p. 356).
} 
Deus foi obrigado a reconhecer, pela experiência do Diabo, que "a irresolução parece ser o vício mais comum e evidente de nossa natureza" (MONTAIGNE, 2016, p. 353). Estando nuas, então, as inclinações morais dos homens, a retidão moral não pode ser deste mundo:

[...] desde que o homem abriu os olhos e percebeu que estava nu, procurou ocultar-se também da vista de seu Artífice; assim a diligência em esconder praticamente nasceu com o próprio mundo e a primeira aparição do defeito, e passou ao uso de muitos por meio da dissimulação. (ACCETTO, 2001, p. 7)

Neste caso, se é próprio do homem a arte de dissimular em meio a um mundo no qual nenhuma norma moral, "ciência ou filosofia pura é guia infalível nas várias circunstâncias da vida” (PÉCORA, 2001, p. XVI), não estaria Machado produzindo "deliberadamente o efeito de que tudo que escreve é também dissimulação” (PÉCORA, 2001, p. XII)? Por esse caminho, a régua que mede o decoro, a clareza e a coerência desse discurso não pertence à ordem do discurso filosófico ou à ordem do discurso da moral cristã. Machado compõe uma ficção que evidencia os frágeis delineamentos dos raciocínios que sustentam os regimes de verdade do pensamento ocidental. Ao denotar pela voz do Diabo que as franjas de algodão, quando puxadas do manto de veludo da rainha, podem desmascarar os alicerces da moral cristã, ele elabora a alegoria da virtude moral como valor contingente. Se "nem Montaigne, nem Pascal, nem La Rochefoucauld trabalham com a forma discursiva fixa dos caracteres" (OLIVEIRA, 2003, p. 126), com Machado de Assis eles ganham um contorno poético distinto de um mapa objetivo dos lugares morais.

O autor contempla o verossímil ficcional como espécie de princípio que puxa as franjas de algodão de uma "vontade de verdade" da moralidade religiosa, da filosofia moral e da própria ficção, enquanto representação da realidade. Ao expor a inconstância dos afetos daqueles que estão submetidos à doutrina da nova igreja, o conto evidencia a presunção exagerada das autoridades, símbolos do bem e do mal, que julgam discernir o virtuoso do vicioso. Essa presunção ${ }^{8}$ já havia sido percebida pelo filósofo Montaigne, fonte pela qual Machado colocou em xeque a racionalidade dos costumes. De fato, ao se tornar o resultado dos efeitos produzidos pelos artifícios, cuja eficácia

\footnotetext{
8 "Quantas coisas pouco verossímeis são afirmadas por gente digna de fé! Se seus testemunhos não bastam para nos convencer, sejamos ao menos prudentes em nosso julgamento, pois considerá-las impossíveis é vangloriar-se de saber até onde vão a possibilidade e a impossibilidade, o que, sem dúvida, é presunção exagerada" (MONTAIGNE, 2016, p. 212).
} 
também é parcial e contingente, a narrativa desse conto dissimula a verossimilhança como causa final da ficção em destaque. Eis a régua que mede o decoro, a clareza e a conveniência desse discurso narrativo.

Se a verdade é contingente e histórica, não estaria Machado, por meio do discurso ficcional, dissimulando a sua arte de "disfarçar" as suas fundamentações filosóficas? Se, como afirma Torquato Accetto (2001, p. 27), "simula-se aquilo que não é, dissimula-se aquilo que é”, o decoro machadiano é baseado na clareza discursiva, não na filosofia verdadeira, posto que a contradição humana, máxima moral divina e filosófica, é efeito verossímil de uma narrativa que dissimula seus códigos retóricos como virtude discursiva perfeitamente adequada ao gênero em análise. Portanto, nas narrativas de Machado de Assis, qualquer valor tido como essencial, bem como a virtude moral, poderia ser vítima de uma ironia dissimulada pelo favor de um gênero despreocupado com a verdade. Aqui, contrariando Montaigne, "a sinceridade" não é "uma parte essencial do seu método de representação da vida" (AUERBACH, 2009, p. 267). Além disso, o autor se desvencilha da filosofia cuja tese considera, afinal: “[...] tola presunção desdenhar ou condenar como falso tudo o que não nos parece verossímil, defeito comum aos que estimam ser mais dotados de razão que o homem normal" (MONTAIGNE, 2016, p. 211).

O verossímil é o que permite a ponderação do raciocínio pelo qual se atribui o poder de julgar a natureza das coisas à razão filosófica e à metafísica cristã. A verossimilhança é a balança pela qual é possível julgar o que é tido por verdadeiro e por falso, numa determinada realidade histórica. A verossimilhança impõe, na escrita machadiana, o reconhecimento do texto como pura realidade material, permitindo-nos questionar o que é tido como natural, verdadeiro, virtuoso e moral na narrativa pela eficácia do seu efeito, cuja clareza retórica, numa ficção eloquente e engenhosa, é inerente ao decoro de sua forma.

Não há essência moral ou subjetiva a ser descortinada, pois "o ajuste prudente do homem à sociedade e [aos] seus decoros passa a ser visto como mentira e artifício em face da verdade profunda, interna, subjetiva que dotou de complexidade psicológica a noção de sujeito nos séculos XIX e XX" (PÉCORA, 2001, p. XIX).

Assim, a ficção é capaz de consolidar uma reflexão sobre a moral adequada à conveniência que demanda a sua enunciação, posto que tanto o discurso filosófico quanto o religioso estão mais comprometidos com aquilo 
que é, e menos com o que poderia ser, conforme a verossimilhança e a necessidade. $^{9}$

Finalmente, respondendo à pergunta sobre a possibilidade de a virtude ser ensinada, esta leitura entende que Machado constrói uma ficção pela qual o raciocínio sobre os valores éticos e morais deve pressupor que "o homem não é nem há de ser ou realizar nenhuma essência, nenhuma vocação histórica ou espiritual, nenhum destino biológico" (AGAMBEN, 1993, p. 38).

Nesse conto, o que está nua, portanto, é a frágil e contingente moral, pressuposta como passível de ser deliberada racionalmente pelas máximas filosóficas e tida como dádiva divina pelos raciocínios teológicos, bem como a verossimilhança da "eterna" contradição humana, não a natureza do artifício que demanda o reconhecimento da eficácia verossímil da elocução que o representa, muito menos a determinação subjetiva do autor, cujo engenho dissimula ser coisa tão mundana a perene e extraordinária agudeza de sua ficção.

\section{Referências}

ACCETTO, Torquato. Da dissimulação honesta. Trad. Edmir Missio. São Paulo: Martins Fontes, 2001.

AGAMBEN, Giorgio. A comunidade que vem. Trad. António Guerreiro. Lisboa: Editorial Presença, 1993.

AGOSTINHO, Santo. A doutrina cristã: manual de exegese e formação cristã. São Paulo: Paulus, 2002.

ARISTÓTELES. Ética a Nicômaco. Tradução e notas Luciano Ferreira de Souza. São Paulo: Martin Claret, 2016.

ASSIS, Machado. 50 contos de Machado de Assis. Seleção, introdução e notas John Gledson. São Paulo: Companhia das Letras, 2007.

AUERBACH, Erich. Mimesis: a representação da realidade na literatura ocidental. São Paulo: Perspectiva, 2009.

BRANDÃO, Jacyntho Lins. "A poética de Aristóteles é uma teoria da literatura?" In: Sobre a arte poética. 1. ed. Tradução Antônio Mattoso, Antônio Queirós Campos. Belo Horizonte: Autêntica, 2018. p. 7-16.

HANSEN, João Adolfo. “Autor”. In: Palavras da crítica. Rio de Janeiro: Imago, 1992. p. 11-45.

\footnotetext{
9 “A necessidade (anánke), por seu lado, pode-se entender como a concatenação das ações que, não só na tragédia, devem caracterizar o mito (isto é, o enredo que se mimetiza), de tal modo que, transpondo-se ou suprimindo alguma parte, se modifique ou desarranje o todo" (BRANDÃO, 2018, p. 14).
} 
MANUEL, D. João. El conde Lucanor. Edición y version actualizada de Juan Vicedo. Biblioteca Virtual Miguel de Cervantes, 2004. Disponível em: <http://www.cervantesvirtual.com/nd/ark:/59851/bmc280k8>. Acesso em: 23 jun. 2020.

MONTAIGNE, Michel de. Ensaios. 1 ed. Tradução e notas Sérgio Milliet. Apresentação Andre Scoralick. São Paulo: Editora 34, 2016.

OLIVEIRA, Ana Lúcia de. Por quem os signos dobram: uma abordagem das letras jesuíticas. Rio de Janeiro: EdUerj, 2003.

PÉCORA, Alcir. Apresentação. In: Da dissimulação honesta. Trad. Edmir Missio. São Paulo: Martins Fontes, 2001.

PELIKAN, Jaroslav. A tradição cristã: uma história do desenvolvimento da doutrina - o surgimento da tradição católica 100-600. v. 1. Tradução Lena Aranha, Regina Aranha. São Paulo: Shedd Publicações, 2014.

RICOEUR, Paul. Ser, essência e substância em Platão e Aristóteles. Tradução Rosemary Costhek Abilio. São Paulo: Editora WMF Martins Fontes, 2014.

SCHWARCZ, Lilia Moritz. As barbas do imperador: d. Pedro II, um monarca nos trópicos. São Paulo: Companhia das Letras, 1998.

SCORALICK, Andre. "Apresentação”. In: Ensaios de Michel de Montaigne. 1 ed. Tradução e notas Sérgio Milliet. São Paulo: Editora 34, 2016. p. 13-33.

SILVEIRA, Eliana Ávila. Cultura e poder na baixa Idade Média castelhana: o livro das armas de d. João Manuel (1282-1348). Tese de Doutorado (História). Orientadora: Fátima Regina Fernandes. Universidade Federal do Paraná, Curitiba, 2005, $272 \mathrm{p}$.

WEBER, Caroline. Rainha da moda: como Maria Antonieta se vestiu para a Revolução. Rio de Janeiro: Zahar, 2008.

ANTÔNIO JOAQUIM PEREIRA NETO é doutor em Memória: Linguagem e Sociedade, pela Universidade Estadual do Sudoeste da Bahia (UESB). Atualmente é professor de português e literatura do Instituto Federal da Bahia, Campus Paulo Afonso. (Dhttps://orcid.org/0000-00024792-0686. E-mail: antoniojoaquimpereiraneto@gmail.com. 